

\title{
Constitucionalismo partisano de derecha en el Chile contemporáneo
}

\author{
Right-wing portison constitutionolism in \\ contemporary Chile
}

* Fernando Muñoz L.

\section{Resumen}

Este artículo propone el concepto de constitucionalismo partisano a fin de comprender la manera en que las instituciones y procedimientos del constitucionalismo moderno son utilizadas en la consecución de objetivos partisanos de corto y largo plazo. Se ilustra este concepto mediante un estudio de estrategias de constitucionalismo partisano empleadas por la derecha en la política chilena contemporánea.

Palabras clave: política constitucional, constitucionalismo partisano, constitucionalismo de derecha, Chile.

\begin{abstract}
This article puts forward the concept of partisan constitutionalism in order to understand the form in which the institutions and procedures of modern constitutionalism are used in the struggle to advance short and long-term partisan objectives. It illustrates this concept with a study of partisan constitutionalism strategies deployed by the right in contemporary Chilean politics.
\end{abstract}

Keywords: constitutional politics, partisan constitutionalism, right-wing constitutionalism, Chile. 


\section{Introducción: el constitucionalismo partisano como categoría de la política constitucional}

Al momento de concluir este trabajo, la prensa informó a la opinión pública internacional de un sorprendente evento: el Presidente de Brasil, Michel Temer, logró que el Senado aprobara una reforma constitucional que consagra medidas de austeridad fiscal destinadas a durar durante las próximas dos décadas. La propuesta de Temer, de llegar a ser aprobada también por la Cámara de Diputados, significará transformar en una regla constitucional, destinada a prevalecer por sobre la legislación futura, una medida de política fiscal que restringe la capacidad estatal de llevar a cabo intervenciones de carácter redistributivo. Si hubiésemos de identificar a los ganadores y perdedores de tal propuesta, no cabe duda de que habríamos de señalar, respectivamente, a los ricos contribuyentes tributarios y a las pobres clases populares. Si hubiésemos de adscribir una orientación política a tal propuesta, no cabría sino calificarla como una medida de carácter neoliberal y, en el contexto específico de la salida del Partido dos Trabalhadores del poder ejecutivo, de derecha.

La iniciativa de Temer corresponde a un caso paradigmático de utilización marcadamente partisana de potestades constitucionales; en este caso, de la potestad de reforma constitucional. Aquí denominaré como constitucionalismo partisano toda aquella praxis político-partidista que emplea instituciones y procedimientos de carácter constitucional a fin de hacer avanzar los intereses inmediatos y de largo plazo del respectivo sector político. Los actores que practican el constitucionalismo partisano tratan las instituciones y procedimientos contenidos en los textos constitucionales como un campo de batalla más en el cual librar su lucha políticopartidista. En este caso, y debido a los contenidos específicos de la iniciativa de Temer, hablaré específicamente de constitucionalismo partisano de derecha o, para simplificar, de constitucionalismo de derecha.

El ejemploya señalado es aún más significativo si se toma en cuenta que Temer llegó a la presidencia brasileña tras un proceso de impeachment que removió a la presidenta Dilma Rouseff, caso que ha sido caracterizado por numerosos comentaristas como un caso de 'golpe blanco', analogando a través de dicho término la salida de Dilma del poder ejecutivo con las situaciones que afectaron al Presidente de Honduras Manuel Zelaya, arrestado por el ejército y exiliado tras haber desobedecido una sentencia de la Corte Suprema de su país que le ordenaba no llevar a cabo un plebiscito, y al Presidente de Paraguay Fernando Lugo, depuesto tras un rapidísimo proceso de acusación constitucional que no le proporcionó ni siquiera tiempo para preparar su defensa contra los cargos que se le formulaban. Por añadidura, al caracterizar como un 'golpe' estas salidas prematuras del ejecutivo, los comentaristas suelen hacer alusión a otros casos situados aún más atrás en el tiempo; particularmente, al golpe de estado que afectó en 1973 al Presidente de Chile Salvador Allende. 
Sin embargo, a mi juicio, la comparación entre estos casos oscurece más que esclarece, pues no se toma suficientemente en serio el hecho de que, a diferencia del caso de Allende, e incluso del caso de Zelaya, es muy difícil emplear el discurso de la legalidad -implícita pero inequívocamente presente en el concepto de'golpe'como su anverso conceptual- para cuestionar la legitimidad de la salida del ejecutivo de Lugo y de Dilma, pues ambos procesos se sujetaron a los procedimientos previstos por las respectivas constituciones de dichos países. ${ }^{2}$ Así, el subsumir de manera indistinta los cuatro casos en cuestión bajo el paraguas de la ilegalidad mediante el concepto de 'golpismo' resulta en un reductivismo particularmente anacrónico; congelado en otra época histórica. Esto, ya que formas de acción partisana propias de la era del neoliberalismo globalizado, época en la cual se ha acelerado e incrementado la exigencia de someterse a la legalidad nacional y supranacional, son entendidas como meras variaciones de formas de acción partisana propias de la guerra fría, época en la cual la comunidad internacional estaba explícitamente dividida en dos y estaba, por ello, dispuesta a hacer vista gorda de aquellos casos de ilegalidad partisana ocurridos dentro de la órbita de influencia de alguna de las superpotencias de la época; situación ejemplificada, desde cierta perspectiva, en el golpe contra Allende. Y si el estudio de la relación entre acción partisana y constitucionalismo quiere captar con claridad histórica los eventos que concitan su interés, entonces dicho estudio debe rehusarse a leer la acción partisana en la era neoliberal a la luz de la acción partisana propia de la guerra fría.

En otros términos, el estudio de la política constitucional debeintentar explicar cómo se lleva a cabo la acción partisana hoy en día dentro de las coordenadas geopolíticas, culturales, e institucionales de la globalización neoliberal, caracterizadas por la juridificación del discurso público mediante el lenguaje de los derechos fundamentales y de los principios constitucionales, la juridificación de la política doméstica mediante instituciones y procedimientos positivizados constitucionalmente, y la juridificación del intercambio económico global a través de tratados internacionales y tribunales de alcance transnacional. Desde luego, la fuerza de la juridificación no se deja sentir de manera homogénea a través de las distintas esferas de la vida social ni, mucho menos, a lo largo y ancho de la desigual topografía del mundo neoliberal, donde la juridificación neoliberal afecta de distintas maneras a los distintos demos y sus respectivas polis. En la época neoliberal, el respeto a la legalidad es un recurso más a utilizar en la competencia económica global.

Mi punto, en consecuencia, es que la noción de 'constitucionalismo de derecha' debiera ser reconocida como una categoría de la política constitucional en su propio mérito. El desafío teórico que plantea este camino consiste en dejar de entender estrategias de política constitucional propias de la contemporaneidad neoliberal, ejemplificadas en los casos de Lugo y de Dilma, a la luz del estrategias partisanas propias de la guerra fría, ejemplificadas en el golpe de Estado en el Chile de 1973. Incluso más, como sugeriré en breve, el empuje de este esfuerzo revisionista puede llevarnos a 
rediscutir la comprensión prevaleciente de este último caso, a fin de evidenciar que se trata del punto de partida de una de las manifestaciones de constitucionalismo de derecha más exitosos de la región de las últimas décadas.

¿Es posible construir una teoría comparada del constitucionalismo de derecha? Mi intuición es que esa posibilidad depende de una previa construcción de tipologías y clasificaciones articuladas a nivel de los estados nacionales. El estado, incluso en la era neoliberal, sigue siendo el espacio orgánico de la política constitucional, puesto que, en cuanto campo de batalla partisana, ella está precisamente orientada a apoderarse de los recursos simbólicos y políticos de la forma de legalidad estatal más elevada, la constitucionalidad. Una teoría del constitucionalismo de derecha debe comenzar, en consecuencia, en el ámbito doméstico estatal, para ir avanzando acumulativamente a partir de esa línea de base.

En este trabajo me aproximaré a la idea de constitucionalismo de derecha a partir del caso chileno. Este caso presenta características que le hacen servir de excelente punto de partida para una reflexión sobre la acción partisana que la saque del contexto de la guerra fría y la traiga al presente neoliberal. Quizás la mejor razón de que el caso chileno sirva este propósito se debe precisamente a que la salida del poder de Allende está registrada en el imaginario político mundial como el caso paradigmático de intervención partisana característica de la guerra fría. El general Augusto Pinochet, en ese sentido, se ha transformado en la cara paradigmática, la caricatura incluso, del militar golpista latinoamericano. Tras el descubrimiento de sus cuentas secretas en el banco Riggs, ni siquiera la derecha chilena está dispuesta hoy a disputar esa caracterización; dichas cuentas lograron destrozar la imagen que la derecha tenía de Pinochet como un estadista virtuoso que, al igual que el dictador romano Cincinato, asumió la dictadura para salvar la república. La destrucción de esta ficción es, desde luego, un desenlace positivo. Sin embargo, no podemos permitir que, junto con ello, desaparezca la conciencia de un hecho que, si bien no debe su existencia a las habilidades o destrezas de Pinochet, sí nos obliga a abandonar la caricatura putschista. Me refiero al hecho de que el golpe de estado en Chile, a diferencia de la mayoría de las dictaduras militares latinoamericanas, logró instaurar un régimen social e institucional que ha mostrado hasta el momento una asombrosa resilencia, expresada en el hecho de que no sólo el modelo económico, social y político instaurado por la dictadura sino también la Constitución promulgada fraudulentamente durante dicho período se han mantenido, con cambios mínimos, tras el fin de la guerra fría y el advenimiento de los gobiernos civiles de centro-izquierda de la Concertación en 1990.

Hablar de constitucionalismo de derecha, en el caso chileno, supone hablar del proyecto político que le ha dado conducción a dicha praxis partisana. La historia de dicho proyecto comienza en 1967, cuando el estudiante de derecho Jaime Guzmán, perteneciente a las tradicionales familias aristocráticas chilenas, funda el así llamado Movimiento Gremialista, una agrupación ultraconservadora y militantemente católica, a fin de resistir el avance de la izquierda en la Universidad Católica de Chile. Este 
contexto le permitió a Guzmán comenzar a desarrollar un discurso político centrado en la crítica de la 'politización' de la sociedad civil, esto es, de la movilización social en pos de transformaciones estructurales. Durante el gobierno de Allende, Guzmán, a esas alturas ya docente de derecho constitucional en la misma casa de estudios, se transformó en un reconocido dirigente opositor; $y$, tras el golpe, en el más importante asesor constitucional de la Junta Militar. Tras la entrada en vigencia en 1981 del texto constitucional en cuya redacción participó, Guzmán percibió que el futuro de su proyecto político dependía de la capacidad de adecuar sus estrategias al contexto de normalidad constitucional que dicho documento preveía que comenzaría hacia fines de la década. Por ello, en 1983 Guzmán fundó un partido político, la Unión Demócrata Independiente (UDI); y en las primeras elecciones parlamentarias hacia fines de la dictadura, en 1989, compitió por un escaño senatorial. Pese a que Guzmán obtuvo tan sólo un $17 \%$, quedando por detrás de los dos candidatos de centroizquierda que obtuvieron cada uno de ellos en torno a un 30\%, el sistema electoral implementado por la dictadura le permitió llegar al Senado. En 1991, una de las últimas células del movimiento militar de izquierda todavía operativas puso fin a su vida; pero el partido que organizó, y el ecosistema político-intelectual articulado en torno a él, ha mantenido hasta el día de hoy un protagonismo central en la utilización de los procedimientos e instituciones constitucionales con el propósito de defender el modelo neoliberal.

La tradición del moderno constitucionalismo de derecha chileno encuentra su hora cero en el golpe de estado de 1973, el que le dio la posibilidad a un reducido grupo de abogados y economistas de derecha de transformar radicalmente la sociedad, la política, la economía y la cultura chilenas. El golpe de 1973 es, en ese sentido, más que un simple putsch; tanto ese evento como los actos de violencia política habitualmente subsumidos bajo la categoría de violaciones a los derechos humanos deben ser entendidos como actos de instrumentalización de la violencia con el objetivo de llevar a cabo transformaciones políticas de carácter constituyente. Durante el período en que se redactó el texto constitucional, el cual va de 1973 a 1980, la estrategia medular del constitucionalismo de derecha chileno fue el atrincheramiento constitucional; ${ }^{3}$ el insertar sus intereses de corto y largo plazo en el texto constitucional, cuya rigidez fue reforzada a través de reglas de modificación considerablemente más difíciles de satisfacer que las que contenía la Constitución anterior. Desde el fin de la dictadura y la llegada al poder ejecutivo de la centro-izquierda en 1990, la UDI, y en general la derecha chilena, ha explotado hábilmente todas las posibilidades de utilización partisana de las instituciones y procedimientos del estado constitucional de derecho. Particularmente importante ha sido la obstaculización de toda reforma significativa al entramado constitucional y legislativo legado por la dictadura mediante el poder de veto que le dan a los parlamentarios de derecha los altos quórums de reforma constitucional y de aprobación de leyes contemplados por el texto constitucional. Esa estrategia ha estado acompañada por la formación de opinión pública a través del periódico El Mercurio, invariablemente comprometido con las facciones más 
intransigentes de la derecha, y de centros de estudios financiados por el empresariado; por la reproducción de cuadros técnicos y políticos, particularmente mediante el rol desempeñado por la Facultad de Derecho de la Universidad Católica, hasta el día de hoy centro de formación de dirigentes de la UDI y de abogados constitucionalistas cercanos a su agenda; $y$, cuando se vuelve necesario, de estrategias de recurso a la jurisdicción constitucional en sus diversas formas, tanto al Tribunal Constitucional, cuyo rol de revisión de proyectos de ley y decretos administrativos le transforma en una verdadera 'tercera cámara legislativa', como a los tribunales ordinarios mediante el uso de la acción de protección de derechos constitucionales, mediante la cual han podido judicializar iniciativas opuestas al programa político de la derecha.

El estudio del constitucionalismo partisano de derecha en el Chile contemporáneo sugiere la existencia, como parte del repertorio de modos de actuar de dicho fenómeno, de al menos las siguientes tres estrategias: atrincheramiento constitucional, consistente en la inscripción en el texto constitucional de objetivos de largo plazo e intereses inmediatos del movimiento; partisanización de la judicatura, tanto de la constitucional como de la ordinaria, mediante el nombramiento de jueces que suscriben los objetivos partisanos de largo plazo de la autoridad que los nombró, de tal manera de asegurar la legitimación judicial de reglas partisanas de rango constitucional o legislativo; obstrucción legislativa, consistente en la utilización de procedimientos constitucionales para impedir la realización de reformas; y litigio constitucional, consistente en la utilización de la jurisdicción constitucional. Distintos casos de constitucionalismo partisano, desde luego, adoptarán las estrategias que se adecúen a sus propios objetivos y al escenario constitucional en el cual se desenvuelven. En este sentido, lo que ofrezco aquí se trata de un esfuerzo prematuro y tentativo por identificar algunas estrategias típicas del repertorio del constitucionalismo de derecha en estudio. Debido a que en un anterior trabajo estudié lo que considero el caso más sostenido de litigio constitucional llevado a cabo por el constitucionalismo de derecha chileno contemporáneo, el litigio contra la píldora del día después (Muñoz 2014), en este lugar me concentraré en ofrecer casos que ilustran las estrategias de atrincheramiento constitucional, de partisanización de la judicatura y de obstrucción legislativa.

\section{Atrincheramiento de reglas que debilitan a los sindicatos}

Durante el período que precedió al golpe de Estado, los sindicatos habían sido uno de los principales instrumentos del conflicto social redistributivo. Socavar la fuerza de ellos a futuro era, en consecuencia, un objetivo estratégico de la derecha. Es importante, en consecuencia, comprender la importancia que el sindicalismo tenía antes de 1973. Sus luchas y movilizaciones fueron responsables de importantes conquistas durante la vigencia de la Constitución de 1925, ejemplificadas en el incremento sostenido de prestaciones sociales y el aumento real de los salarios durante la segunda mitad de los $60^{\prime}$ y los primeros años 70'. 
Al menos tres razones explican esta capacidad del sindicalismo de incidir en la distribución de la renta nacional. La primera consiste en el esfuerzo de los trabajadores de articularse unitariamente, lo que se expresó durante el período de 1953 a 1973 en la existencia de una organización multisindical que agrupaba a los principales sindicatos y federaciones sindicales chilenas, la Central Única de Trabajadores (CUT). La segunda corresponde a la politización de la CUT, expresada en la proclamación de diversas transformaciones estructurales en la sociedad chilena como objetivos programáticos de la propia organización multisindical. La tercera consiste en el incremento paulatino de los niveles de afiliación sindical de la totalidad de los trabajadores, llegando hasta llegar a comprender a un tercio de la fuerza laboral hacia el período de la Unidad Popular, el mayor nivel de sindicalización en la historia chilena.

Ahora bien, ¿qué explica el incremento en la tasa de sindicalización durante los períodos de Frei y Allende? Para dar con la respuesta, es necesario tener presente que durante el período que va de los años 30' a 1973 hay ciertas circunstancias que varían y otras que se mantienen estables. Entre las circunstancias que varían se encuentra la actitud de los Ejecutivos hacia la movilización sindical y la protesta popular en general, actitud que durante gran parte del período consistió en la represión e incluso en la matanza de trabajadores o pobladores movilizados, como ocurrió en Ránquil (1934), Plaza Bulnes (1946), José María Caro (1962), El Salvador (1966), Pampa Irigoin (1969). En cambio, durante los gobiernos de Eduardo Frei (1964-1970) y Allende (1970-1973), el Ejecutivo abrazó públicamente un discurso de reivindicación de los intereses de los sectores populares. Si bien el programa de la 'promoción popular' de Frei no implicó que no haya habido casos de represión durante su gobierno, durante el gobierno de Allende se tradujo incluso en el uso del control de la fuerza pública, que el Ejecutivo detentaba constitucionalmente, con el fin de prevenir el desalojamiento violento de pobladores de terrenos en ocupación, lo que supuso dejar sin ejecución resoluciones judiciales que ordenaban el desalojo de los mismos. Estos cambios a nivel de la actitud del Ejecutivo parecieran haber incidido en la disposición al involucramiento social de todo tipo, incluyendo el sindical.

Una circunstancia, en cambio, que se mantiene estable durante todo el período es la regulación legal de la sindicalización. Ella favorecía la consolidación de la membresía sindical estableciendo la inscripción automática de los trabajadores en los sindicatos industriales ya constituidos. Así, el artículo 382 del Código del Trabajo señalaba que en los sindicatos industriales que hubiesen obtenido personalidad jurídica -la cual se obtenía presentando una solicitud con tal objeto ante la Inspección del Trabajo"se considerarán sindicalizados todos los obreros de la empresa, fábrica o industria". Entonces, si bien la existencia de un sindicato en una determinada empresa era algo que debía ser requerido, solicitado, no algo que el régimen jurídico estableciera ipso facto, al menos una vez que aquel estuviese constituido, la incorporación de nuevos miembros era un asunto automático. ${ }^{4}$ 
Ahora bien, para los sectores civiles que apoyaron el golpe y dieron sustento y conducción política a la dictadura, los resultados de la movilización sindical tenían un carácter negativo. Jaime Guzmán criticaba la existencia de "sindicatos politizados, o lo que es peor, erigidos en grupos de presión más fuertes que el propio Estado y capaces de obtener injustos privilegios que además perjudican gravemente la economía", los que, a su juicio, contribuían al conflicto social generando "un cuadro social de huelgas generalizadas y permanentes" (Guzmán 1991, 339). Por su parte, los economistas que asesoraron a la Junta Militar conocidos colectivamente como los 'Chicago Boys' también consideraban como perjudicial para el funcionamiento de la economía que "los distintos grupos sociales o de presión se organicen y traten de utilizar los recursos del Estado en su directo beneficio" (De Castro 1992, 30).

El movimiento sindical era, en el alineamiento de amigos y enemigos articulado por la Junta Militar, un enemigo importantísimo. Ello explica que una de las primeras medidas llevadas a cabo tras el golpe de Estado fuese la cancelación de la personalidad jurídica de la CUT a través del Decreto Ley № 12, de 17 de septiembre de 1973, "por haberse transformado en un organismo de carácter político, bajo la influencia de tendencias foráneas y ajenas al sentir nacional". Asimismo, el Decreto Ley en cuestión prohibió “toda organización y acción, propaganda de palabra, por escrito o por cualquier otro medio, que revelen, directa o indirectamente su funcionamiento". Paralelamente, las fuerzas armadas desencadenaron un proceso de persecución, amedrentamiento y asesinato de dirigentes sindicales que duró durante todo el período de la dictadura. Finalmente, el 'Plan Laboral' de 1979, comprehensiva reforma al derecho sindical contenida en cuatro decretos leyes, restringió la negociación al interior de cada empresa y permitió evitar la paralización de actividades a través de medidas que autorizaban el reemplazo de trabajadores en caso de huelga.

La discusión al interior de la Comisión de Estudios de la Nueva Constitución (CENC), el órgano de asesores constitucionales que redactó el anteproyecto constitucional de la dictadura, evidenció el profundo rechazo hacia los elementos que habían permitido el éxito del sindicalismo durante la vigencia de la Constitución de 1925. Así, por ejemplo, en la Sesión 195, el Ministro del Trabajo, Sergio Fernández, argumentó que "es preciso que se consagre constitucionalmente que las organizaciones libres no deben tener compromisos partidistas" y que se le diera "rango constitucional a la incompatibilidad entre ser militante de un partido político y dirigente sindical". También criticó el sentido mismo del actuar sindical en el período anterior, declarando que el deber de los sindicatos debía ser el "satisfacer las necesidades u obtener beneficios para los afiliados al sindicato" pero en un sentido "subordinado siempre al bien común". Pareciera ser que para Fernández, el incremento de la participación de los trabajadores en el ingreso nacional iba contra el bien común. Y el principal instrumento de presión de los trabajadores, la huelga, era para Fernández "un instrumento que ha sido usado por ciertos grupos políticos como un instrumento de la lucha de clases", que "crea odiosidades, desconfianza" y que, en última instancia, "es la forma en que se 
manifiesta la fuerza, la ley del más fuerte". Sergio Diez llegó a afirmar, secundando a Fernández, que "la huelga es una expresión de la barbarie" (i!). Pinochet, por su parte, en su memorándum Normas para la Nueva Constitución, enviado a la CENC en 1977, planteó que la Constitución debía perseguir el objetivo de lograr la "[s]uperación de la huelga como instrumento válido para enfrentar los conflictos laborales". Así lo presentaba José Piñera, como Ministro del Trabajo, en la Sesión Secreta Legislativa de la Junta Militar de 25 de junio de 1979:

[E]n la forma en que está concebido el esquema de huelga en el proyecto de negociación colectiva, con reemplazo de los sindicatos comunistas que se declaran en huelga, éstos se irían prontamente para afuera, porque precisamente la idea de formar un sindicato comunista en este esquema, se traduce en un suicidio de los comunistas.

El objetivo de disminuir la fuerza de los sindicatos se plasmó en diversas reglas constitucionales y legislativas. Así, por ejemplo, la Constitución prescribe en su artículo 19 № 19 que las "organizaciones sindicales no podrán intervenir en actividades político partidistas" y establece, en su artículo 23, una rígida separación entre lo 'gremial'y lo 'político'. Otra forma de reducir la fuerza sindical consistió en imposibilitar constitucionalmente que futuras leyes establecieran la obligatoriedad de la afiliación sindical o su carácter automático. En la Sesión 206 de la CENC, Guzmán planteó la necesidad de que la Constitución tomara una postura frente a lo que caracterizó como "el problema de la afiliación libre u obligatoria a las organizaciones gremiales que se formen en el campo de una respectiva actividad". Guzmán reconoció que la libre afiliación podía conducir a la atomización de la fuerza laboral en diversas organizaciones o derechamente a la no participación en ellas; pero aún así se inclinó por consagrar la libertad individual en esta materia, aseverando que ella le parecía una "consecuencia natural" de la libertad sindical. Guzmán reforzó este argumento observando que en general le costaba concebir"un derecho que sea obligatorio, porque entonces ya no pasa a ser derecho, sino una función". La Constitución, recogiendo las opiniones de Guzmán, establece en su artículo 19 № 19 que "[l]a afiliación sindical será siempre voluntaria", lo que busca impedir el establecimiento de reglas sobre afiliación sindical como las existentes hasta septiembre de 1973. Así, la fuerza de los sindicatos esté estructuralmente supeditada a un acto individual de afiliación, en línea con la concepción individualista del mundo que sustenta el proyecto neoliberal. Finalmente, el nuevo Código del Trabajo promulgado por la dictadura autorizó el reemplazo de trabajadores en huelga, medida que priva a la huelga de toda capacidad de lograr su objetivo funcional de empoderar a los trabajadores frente a sus empleadores. 


\section{Atrincheramiento y legitimación judicial de reglas que favorecen electoralmente a la derecha}

El segundo caso de atrincheramiento constitucional que me interesa presentar aquí, y que ofrecerá también un ejemplo de legitimación judicial de reglas, corresponde al establecimiento de un procedimiento electoral diseñado para maximizar el resultado de los partidos de derecha y minimizar las posibilidades de representación electoral de los partidos de izquierda. Este objetivo se logró mediante un diseño de distritos electorales orientado a sobrerrepresentar geográficamente a los lugares donde la Junta Militar obtuvo un mejor resultado en el plebiscito de 1988, unido a un peculiar sistema electoral, el así llamado sistema binominal. Dicho sistema fue creado en 1989 mediante una reforma a la Ley de Votaciones Populares y Escrutinios:

Artículo 109 bis.- En el caso de elecciones de Parlamentarios, el Tribunal proclamará elegidos Senadores o Diputados a los dos candidatos de una misma lista, cuando ésta alcanzare el mayor número de sufragios y tuviere un total de votos que excediere el doble de los que alcanzare la lista o nómina que le siguiere en número de sufragios.

Si ninguna lista obtuviere los dos cargos, elegirá un cargo cada una de las listas o nóminas que obtengan las dos más altas mayorías de votos totales de lista o nómina, debiendo el Tribunal proclamar elegidos Senadores o Diputados a aquellos candidatos que, dentro de cada lista o nómina, hubieren obtenido las más altas mayorías.

Si el segundo cargo por llenar correspondiere con igual derecho a dos o más listas o nóminas, el Tribunal proclamará electo al candidato que hubiere reunido mayor cantidad de preferencias individuales.

La particularidad de este sistema es que dificulta la obtención de mayorías parlamentarias y, con ello, dificulta la aprobación de legislación que modifique el status quo, favoreciendo la legislación aprobada durante la dictadura. Dicho sistema también tiende a la conformación de dos coaliciones, debido a que deja automáticamente sin representación a una coalición o partido que obtenga el tercer lugar en las elecciones. Un importante detalle histórico-contextual es que, antes del golpe, el sistema de partidos políticos chileno había estado caracterizado por la existencia de los así llamados 'tres tercios'; es decir, la derecha, el centro, y la izquierda. Si bien la izquierda marxista había sido prohibida constitucionalmente, este sistema se orientaba a asegurar que ella no tendría representación electoral, por cuanto se estimaba que, en la medida en que la izquierda lograse competir electoralmente pese a la prohibición (la cual fue por lo demás revocada en 1989), ella obtendría siempre el tercer lugar y en consecuencia quedaría fuera del Congreso, como de hecho ocurrió.

Desbaratar el sistema de partidos que había permitido el surgimiento de proyectos políticos redistribucionistas representaba, en consecuencia, al mismo tiempo un objetivo de largo plazo y un interés inmediato de la derecha. Podemos encontrar esa preocupación en el Informe de la Subcomisión CENC encargada del estudio del 
Sistema Electoral y del Estatuto de los Partidos Políticos, documento entregado a la CENC en su sesión de 12 de julio de 1978. Podemos leer en dicho Informe que el "sistema electoral proporcional imperante en nuestro país hasta el 11 de septiembre de 1973, a juicio de esta Subcomisión, estimuló la división de la sociedad y agravó la lucha entre los partidos políticos, entidades que, con el tiempo, fueron monopolizando la expresión ciudadana con exclusión casi absoluta de los sectores independientes, lo que contribuyó a la inestabilidad de los gobiernos con gran rotativa de alternativas, exageró el poder de las directivas nacionales de los partidos y creó las condiciones ideales para el surgimiento de las colectividades marxistas." En opinión de sus integrantes, al "favorecer la expresión de todas las opiniones", el sistema representativo "acentúa la función de las oposiciones sin matices y el carácter conflictivo de las sociedades políticas, haciendo difícil el establecimiento de una mayoría permanente de Gobierno".

Los elementos electorales de esta estrategia de distorsión del paradigma democrático fueron introducidos por la Junta Militar mediante una reforma a la Ley sobre Votaciones Populares y Escrutinios promulgada el 16 de mayo de 1989, tras nueve meses de tramitación. Dicho proyecto de ley resolvió dos dudas centrales que aun pendían en materia de organización política: primero, cuál sería la división geográfica del electorado para efectos de la integración de la Cámara de Diputados y el Senado; y segundo, cuál sería el sistema electoral mediante el cual dichas autoridades serían elegidas. En aquel entonces, la Junta Militar ya contaba con un indicador respecto de la tónica electoral del futuro cercano, proporcionado por los resultados del plebiscito de 1988. Así las cosas, la Junta resolvió estas dos preguntas de una manera funcional a su interés por preservar su 'modelo', sobrerrepresentando mediante un diseño partisano de los distritos electorales a los sectores políticamente conservadores y dificultando la traducción de las mayorías electorales en mayorías parlamentarias.

Ahora bien, en un caso que también equivale a una medida de atrincheramiento constitucional, la Constitución de la dictadura había creado una nueva categoría de ley, las leyes orgánicas constitucionales, determinando que las leyes que la Constitución expresamente calificara como tales requerirían de las cuatro séptimas partes de los diputados y senadores en ejercicio para su aprobación, modificación o derogación. Hasta ese entonces, las reglas constitucionales chilenas jamás habían contemplado un quórum legislativo distinto de la mayoría simple de los diputados y senadores presentes. Adicionalmente, la Constitución también había determinado que dichas leyes debían ser revisadas por el Tribunal Constitucional, cuyos integrantes habían sido nombrados por la Junta Militar. El legado político, económico y social de la Junta Militar quedaba así protegido mediante una serie de candados que operan distorsionando la expresión política de las mayorías.

Por tratarse de una materia de rango orgánico constitucional, el proyecto de reforma electoral iniciado por la Junta Militar fue remitido al Tribunal Constitucional para su revisión. La atención de diversas organizaciones políticas, que hicieron llegar 
sus planteamientos al Tribunal, estuvo puesta en la modificación que este proyecto de ley hacía respecto del requisito de residencia de los candidatos a parlamentarios en la región por la que compitieran para la primera elección. El distritaje partisano no pasó, sin embargo, desapercibido para un grupo de profesores universitarios, quienes argumentaron mediante una presentación al Tribunal, de fecha 18 de agosto de 1989, que la organización de los distritos infringía los principios de igualdad política establecidos en el propio texto constitucional de la dictadura. Dichos principios, escribieron, "constituyen la base esencial del ejercicio de la soberanía en una República democrática y el carácter igualitario del sufragio, se ve como una de las expresiones más capitales de aquel deber del Estado y todos sus órganos que se consagra en las Bases de la Institucionalidad", consistente en "asegurar el derecho de las personas a participar con igualdad de oportunidades en la vida nacional". En contraste con ello, y analizando los distritos electorales diseñados por el legislador -esto es, por la Junta Militar-, los peticionarios observaron que "la diferencia del valor del sufragio de un distrito electoral a otro en el proyecto de ley en examen varía de 1 a 5,58, vale decir, un $558 \% "$

Con fecha 12 de mayo de 1989, el Tribunal Constitucional emitió su pronunciamiento respecto a la constitucionalidad del proyecto de ley de la Junta Militar. El Tribunal resumió la petición antes reseñada de la siguiente manera: "el fundamento esencial de la objeción consiste en que no sólo no hay igualdad, sino tangibles diferencias en su conformación, lo que implicaría la infracción de aquellos preceptos de la Carta que tratan de la igualdad de oportunidades para participar en la vida nacional, la igualdad ante la ley, el sufragio igualitario". La respuesta del Tribunal fue sostener que dicho reparo de constitucionalidad "carece de todo fundamento, ya que el constituyente entregó al legislador de la ley orgánica constitucional respectiva la determinación de los distritos electorales". Para el Tribunal, la Constitución dejó "amplia facultad al legislador para determinar los distritos electorales. Ni siquiera consideró conveniente fijarle criterios o pautas de modo que el legislador ha tenido libertad para considerar factores de carácter geográfico, territorial, poblacional, socioeconómicos, estratégicos, etc." El Tribunal, convenientemente, hizo caso omiso de los "criterios o pautas" evidentemente contenidos en los artículos 10,4ㅜ, y 15 de nuestra Constitución, que proclaman sin ambigüedades la igualdad política y la concretizan en el sufragio igualitario.

\section{Obstrucción legislativa de propuestas redistributivas}

La tramitación de la Ley № 19.966, que establece un régimen de garantías en salud también conocido como Plan AUGE (Acceso Universal de Garantías Explícitas) nos ofrecerá un ejemplo de obstrucción de medidas legislativas de carácter redistributivo. En efecto, el Ejecutivo ingresó una propuesta legislativa el 25 de junio de 2002 que contemplaba la creación de un Fondo de Compensación Solidaria orientado a 
"terminar con las diferencias de precio que enfrentan las personas en razón de su sexo, edad y otros factores de riesgo". A instancias de la Comisión de Salud de la Cámara de Diputados se introdujo una indicación estableciendo que "ninguna forma de funcionamiento del Fondo de Compensación Solidario podrá contemplar el traspaso neto de recursos desde el Fondo Nacional de Salud, o desde sus afiliados, hacia las Instituciones de Salud Previsional, o hacia sus afiliados". Dicha indicación, que tenía por propósito asegurar que "el aporte fiscal no [fuera] un subsidio que pueda ser portable por parte de los beneficiarios, sino que [fuera] un aporte al sistema Fonasa para complementar o suplir las cotizaciones en caso de que éstas no se puedan hacer", despertó la oposición de los diputados UDI Julio Dittborn y Gastón von Mühlenbrock, y fue calificada por la senadora UDI Evelyn Matthei como "inaceptable". La discusión era relevante para los grupos de interés que operan en el sistema de salud, pues el fondo no sólo significaría un traspaso "desde las Instituciones de Salud Previsional al Fondo Nacional de Salud que ha sido estimado entre $\$ 15.000$ y $\$ 18.000$ millones" sino que, además, de ser consagrada la imposibilidad de traspasos podía desincentivar el traspaso de cotizantes del sistema público al privado y, más aún, incentivar el camino inverso. 
Demos un salto hacia adelante en la historia. En la Sesión de 4 de agosto de 2004, el proyecto de ley fue aprobado en general por el Senado. La Senadora Matthei intervino para destacar que un proyecto de ley que "en su momento generó discusiones apasionadas, amenazas de paro en los hospitales, protestas de los gremios de la salud, votaciones divididas en la Cámara de Diputados, etcétera", estuviera listo para ser despachado por el Senado "en unos minutos, gracias a que todo viene resuelto prácticamente por unanimidad".

Es precisamente lo inesperado de esta unanimidad, si consideramos la oposición que había despertado anteriormente en los parlamentarios de la UDI, el síntoma que sugiere la existencia de algo más detrás de ella. Disintiendo de la optimista intervención de Matthei, el senador de centro-izquierda Nelson Ávila argumentó que dicha unanimidad se alcanzó "sobre la base de hacer sucumbir el Fondo de Compensación Solidario", al cual calificó como "el alma del proyecto". Para Ávila, tal abandono permitió que el "ámbito privado" se restara "de colaborar en un sistema de salud que está marcado por las gravísimas diferencias económicas existentes en la población", expresadas en una "salud estratificada según la condición económica de los habitantes del país".

Como respuesta, Matthei replicó duramente que "sostener que el Fondo de Compensación Solidario era el alma del proyecto AUGE sólo refleja la ignorancia que suele exhibir alegremente en esta Sala el Senador señor Ávila". La razón de tal descalificación era que, según la Senadora, la centro-izquierda oficialista "tenía los votos suficientes para aprobar el Fondo de Compensación Solidario y no requería los de la Oposición". No había existido un veto opositor en la legislación ya que, como la propia senadora hizo ver, "es una materia de quórum simple, no calificado", por lo que "si el Gobierno decidió conversar con nosotros fue pensando en que ello era lo mejor para el futuro de la iniciativa, y no porque necesitara nuestro apoyo".

A primera vista podría parecer que la senadora Matthei tenía razón en calificar la eliminación del Fondo de Compensación Solidario como un resultado dela deliberación imparcial. Un examen del registro histórico sugiere, sin embargo, algo distinto. Más bien lo que ocurrió fue que en este caso, tratándose de una ley simple donde los quórums no servían para bloquear la iniciativa redistribuidora, los parlamentarios UDI opuestos al proyecto simplemente recurrieron a la barrera de contención última: el Tribunal Constitucional.

En efecto, en la sesión 12 de diciembre de 2002, el diputado UDI Patricio Melero planteó que el proyecto era inconstitucional; afirmación que reiteraron en la sesión de 15 de enero de 2003 los diputados UDI Marcelo Forni y Angélica Cristi en razón de que se afectaba el derecho de propiedad. El Primer Informe de la Comisión del Salud del Senado, fechado el 30 de abril de 2004, señala que en la Discusión General del proyecto el senador de derecha Alberto Espina alegó que "desviar parte de la cotización a la formación del Fondo de Compensación Solidario puede adolecer también de inconstitucionalidad, en la medida en que se priva a los cotizantes de 
una parte de la cotización que les pertenece, de la que no podrán disponer porque la ley lo ha hecho por ellos". En la discusión en particular, el senador Espina precisó aún más su objeción, argumentando que destinar una parte de las cotizaciones de salud "a integrar el Fondo de Compensación Solidario implica el establecimiento de un impuesto encubierto, afecto a un fin específico, y constituye una flagrante violación del derecho de propiedad de cada afiliado respecto de sus propias cotizaciones de salud". Sobre la base de tales argumentos "anunció que se abstendría en la votación de los mismos y que parlamentarios de su sector recurrirán al Tribunal Constitucional para que dilucide estos puntos". A esta reserva de constitucionalidad, como se denomina al anuncio que se hace de la intención de recurrir al Tribunal, se sumó la senadora Evelyn Matthei.

La historia después de esto es simple. En la sesión de 10 de agosto de 2004 el diputado de derecha Francisco Bayo expresó su satisfacción con "la eliminación del Fondo de Compensación Solidario por parte del Senado", la cual, "lo dijimos en esta Sala y también en el Senado", tenía "visos de inconstitucionalidad, y no hay ninguna duda de que así habría sido". ¿Y cómo se resolvió la discrepancia política entre los partidarios y los detractores del Fondo? El Ejecutivo, interesado en lograr la aprobación del proyecto de ley, retiró la indicación ante el anuncio de los parlamentarios de derecha de recurrir al Tribunal Constitucional. En suma, el Tribunal Constitucional funcionó aquí como un mecanismo de obstrucción del proceso legislativo, al proporcionar a los parlamentarios de la UDI de una amenaza creíble de que impedirían la aprobación de la creación del proyecto AUGE de no ser retirado el Fondo de Compensación Solidario del mismo.

\section{A modo de conclusión: el estudio de la política constitucional en la era del retorno de la política}

El período que va de la caída del muro de Berlín a la crisis económica de 2008 pareciera haber representado un retroceso de la política que, de ser un espacio de contestación de la relación entre capitalismo y democracia, como lo había sido durante el 'corto siglo XX', pasó a transformarse en un ámbito de desnuda gestión tecnocrática. Diversos eventos ocurridos desde el 2008 en adelante, incluyendo significativas oleadas de movilización social a partir de 2011, parecieran indicar la existencia de un proceso de acelerada descomposición de la legitimidad del modelo global neoliberal consolidado tras la caída del muro. Por añadidura, el reciente triunfo de Donald Trump en las elecciones presidenciales norteamericanas ha atraído considerable atención hacia las manifestaciones populistas antiliberales. Las perspectivas que abren estos eventos para el estudio de la política constitucional, particularmente del constitucionalismo partisano, son significativas. En efecto, abundan las señales de que el 'retorno de la política' que estamos experimentando aumentará la importancia del estudio del constitucionalismo partisano, Gobiernos populistas de derecha como el 
del partido Fidesz en Hungría ya han llevado a cabo estrategias de atrincheramiento constitucional y de partisanización de la judicatura. Así y todo, las perspectivas de dicho análisis deben contemplar la posibilidad de que la reacción contra la globalización derive en una destrucción del entramado de tratados de libre comercio que hacen posible el libre movimiento de capitales a lo largo y ancho del mundo. En la medida en que el retorno de la política no acabe con la globalización neoliberal, el respeto por la legalidad nacional e internacional mantendrá el valor que detenta hoy en día, lo cual seguirá asegurando la importancia y vitalidad del constitucionalismo partisano. No está de más tener en consideración, sin embargo, que los tiempos que vivimos nos han recordado que, cuando se trata de imaginar el futuro, no podemos dar nada por sentado. 


\begin{abstract}
Notas
'Es importante hacer esta salvedad, pues en países como España o Chile el 'atrincheramiento' de medidas de austeridad a nivel constitucional, legislativo o administrativo ha sido propuesto por partidos políticos tradicionalmente caracterizados como de izquierda. Si bien el Partido dos Trabalhadores también ha experimentado un desplazamiento hacia posiciones neoliberales, su hegemonía política y electoral desde la llegada de Luiz Inácio Lula da Silva a la presidencia se ha sustentado en gran medida en políticas de gasto social que se verían gravemente dificultadas con la reforma constitucional propuesta por Temer.

${ }^{2}$ La solución a este dilema, en el caso de Lugo, consistió en un primer momento en anunciar su intención recurrir al sistema interamericano de derechos humanos, invocando así la supralegalidad internacional en reemplazo del lenguaje de la legalidad nacional. Como se ve, también Lugo intentó emplear de manera partisana una forma de legalidad, en este caso la del derecho internacional de los derechos humanos.

${ }^{3}$ Empleo la expresión 'atrincheramiento constitucional' como un calco semántico del concepto inglés de constitutional entrenchment.

${ }^{4}$ Esta regla operaba respecto de los sindicatos industriales; respecto de los sindicatos de profesionales, el Código establecía la necesidad de que los trabajadores que se incorporasen a la empresa solicitaran activamente su afiliación al sindicato. Detrás de esta distinción se encontraba la distinción contenida en el artículo $1^{\circ} \mathrm{del}$ Código entre empleado, "toda persona en cuyo trabajo predomine el esfuerzo intelectual sobre el físico", y obrero, todo aquel que "trabaje por cuenta ajena en un oficio u obra de mano o preste un servicio material determinado".
\end{abstract}

\title{
Referencias
}

DE CASTRO, S. (1992), El Ladrillo: Bases de la Política Económica del Gobierno Militar Chileno, Santiago, Centro de Estudios Públicos.

GUZMÁN, J. (1991), El Miedo y Otros Escritos, Estudios Públicos 42:251-570.

MUÑOZ, F. (2014), Morning-After Decisions: Legal Mobilization Against Emergency Contraception In Chile, Michigan Journal of Gender \& Law 21: 123-175.

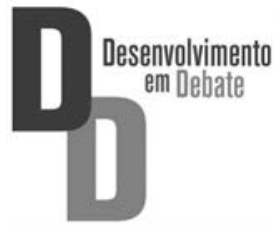

